\title{
UMA LEITURA DE ESCRITA TRAUMÁTICA EM DUAS DRAMATURGIAS CONTEMPORÂNEAS BRASILEIRAS: AGRESTE E BR-3
}

Thiago Henrique Fernandes Pereira*

RESUMO: O presente texto focaliza a producão dramática brasileira que, mais propriamente a partir da década de 1990, explora a ficcionalidade da errância - personagens em constante trânsito. Abordamos os textos Agreste (2004), de Newton Moreno e $B R-3$ (2005), de Bernardo Carvalho, numa investigação a respeito da forma literária/dramática em sua relação com o deslocamento a partir de termos correspondentes como errância. A violência e a manutenção de uma memória repetida serão elementos que definirão em tais textos sua relação com o referente de enunciação urbano, tal qual, de sua abertura à questão das identidades subjetiva e nacional.

PALAVRAS-CHAVE: dramaturgia contemporânea; errância; luto; identidade; território. thiagohfernandesp@gmail.com

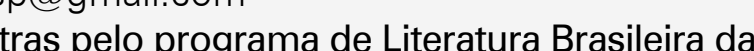
Universidade de São Paulo.

ABSTRACT: This text focuses on a brasilian dramatic production that, more specifically starting from the 1990 s, explores the fictionality of wandering with their characters in constant transit. tionality of wandering with their characters in constant transit. We approach the texts Agreste (2004), by Newton Moreno, and
$B R-3$ (2005) by Bernardo Carvalho, in an investigation about the $B R-3(2005)$ by Bernardo Carvalho, in an investigation about the literary/dramatic form in its relation to the movement, from the corresponding terms as wandering. The violence and the maintenance of a repeated memory are elements that will define in these texts their relationship with the referent of urban enunciation, as is, from its opening to the issue of subjective and national identities.

KEYWORDS: contemporary drama; wandering; grief; identity; territory. 
1. MORENO. A refeição, p. 66 .

2. Composto pelos textos $A$ cicatriz é a flor e Dentro.
Moça - Eu não me lembro da dor. Só do susto. Eu estava lá e vi quando me levou para dentro de você. Eu lembro quando você falou: "Posso te morder? Posso arrancar um pedaço seu?”.

No rol de dramaturgias do recifense Newton Moreno, como no referido trecho de "A refeição: ensaios dramáticos sobre o canibalismo", ou, ainda, no díptico Body Art, ${ }^{2}$ destaca-se um ímpeto vital de encontro, de pertencimento, de possessão, na medida sempre liminar de seus atores e do sentido localizado num constante elaborar de interstícios. Nunca o espaço ocasional, neutro, mas sempre o espaço de conflito que se insinua na investigação do autor por práticas e ritos, muitas vezes implicados em determinado círculo, como o homoerotismo, mas, acima de tudo, revelando um caráter especular; o interesse discursivo, de "voz" se mescla ao interesse formal, estético.

Agreste (2004) pertence a esse mesmo panorama, e em meio às considerações de autoria, em que Newton Moreno declara estar ali interessado mais uma vez nos desdobramentos entre teatro e homoerotismo e numa volta muito pessoa à cultura popular nordestina, à figura do contador, sobressai-se o caráter de "dramaturgia desejante", nas palavras de Antonio Rogério Toscano. Desejo este "da transitividade, do devir criativo", que muito claramente circunscreve o lugar dessa parcela de dramaturgia:
Lá onde dramaturgo, encenador, ator-criador e público (além dos demais criadores por ventura envolvidos no projeto) se reúnem para cravar no espaço e no tempo a sua escritura espetacular. Lá, onde os procedimentos colaborativos modificam o próprio conceito de dramaturgia. Mais longe ainda, lá, onde a relação entre texto e cena está por ser (re-)inventada, é que está a morada do trabalho de Newton Moreno como dramaturgo contemporâneo. ${ }^{3}$

Se tomarmos de empréstimo tal localização do conceito de dramaturgia e o estendermos a outro exemplo que nos ocupa, a saber, $B R-3$, de Bernardo Carvalho, ele ainda vigora apesar de se tratarem de resultantes distintas. $B R-3$, que não chega a ser editorado, alcança-nos, de modo geral, já no limite de sua afirmação partilhada, já é ele, como num arquivo estabelecido, junto do trabalho do Teatro da Vertigem e de Bernardo Carvalho, toda uma gama de textos confluindo para um ponto comum, tal qual a corrente do rio Tietê, seu espaço de realização, cruzando a cidade de São Paulo. Textos procedentes do advento documental e investigativo que perpassa a cena contemporânea; documento que assinala uma lógica confessual que contrariaria a máquina criativa através do gesto de implicar, em alguma instância, legitimidade social; textos-objetos em acordo com a ressignificação, "a partir da expansão semiótica e do pensamento pós-estruturalista”, que sofre a
3. TOSCANO. Agreste: uma dramaturgia desejante, p. 106.
EM TESE $\quad$ BELO HORIZONTE $\quad$ v. $21 \quad$ N. $2 \quad$ MAO-AG0. $2015 \quad$ PEREIRA. Uma leitura de escrita traumática em duas dramaturgias [...] $\quad$ P. 136-146

Crítica Literária, outras Artes e Mídias 
5. SARRAZAC. A invenção da teatralidade, p. 57.

6. SARRAZAC. O futuro do drama, p. 9.

7. SARRAZAC. Sobre a fábula e o desvio, p. 88. noção mesma de texto, abarcando todo um conjunto de "práticas significantes", como esclarece Ileana Diéguez Caballero. ${ }^{4}$

Em ambos os casos, conservadas as especificidades de gestão de cada uma das obras, a qualidade desejante é dado que aponta para o quadro histórico no qual a conformação teatral pela arte da cena e pela literatura dramática conjugadas sofre um abalo, convocação e ruptura de teatralidades. Mas, conquanto o teatro, na passagem do século XIX para o XX "toma consciência de seu vazio interior e projeta esse vazio para o exterior", ${ }^{5}$ não mais se atualizando no limite do modelo dramático, a autonomia será também da palavra. Autonomia performativa que ilumina um estado fronteiriço - variedade de procedimentos composicionais em diálogo.

Em se tratando de um texto dramático híbrido, a garantia de unidade cede lugar ao caráter movente, no sentido de que há implicação de movimento ao assentamento de gênero. Liberdade de escritura, de estruturação, aproximada do romance, assim defendido por Jean-Pierre Sarrazac. Numa perspectiva "contra naturam", ${ }^{6}$ antípoda ao modelo aristotélico, o professor e ensaísta francês convida a investigar sobre as novas configurações da fábula, das fábulas possíveis, "mosaico de formas breves".

Entendido o panorama e tendo-o como referencial, é de nosso interesse propor uma leitura que problematize as duas obras, Agreste e BR-3, nos horizontes da dramaturgia e da literatura brasileiras contemporâneas simultaneamente. Para tanto, tomamos um ponto de comunhão à elaboração de ambas, independentemente do afunilamento temático, sendo o deslocamento físico pelo espaço geográfico brasileiro, espécie de argumento dramatúrgico focado na condição não nucleada do indivíduo, disfunção do referente residencial. Comunhão fundada no devir errante, potência esclarecedora do fluxo que se estabelece entre os motivos ficcionais e a clareza ou maior exposição dos procedimentos de composição e de crítica.

Agreste perfura "o Brasil mais fundo". ${ }^{8} \mathrm{O}$ faz através de uma estrutura de contação - voz perfurando a memória -, e através do "homem sertanejo", representado aqui pelo casal formado por duas mulheres, uma que se traveste de homem, e assim se reconhece, silenciosamente, tal qual a consciência de seu amor. Ao romper com a lógica de pertencimento terreno, partem para o desconhecido. BR-3 deslumbra-se com a nossa geografia traçando o mapa de três brasis: Brasilândia, Brasília, Brasileia. Espaços os mais diversos que se sobrepõem, surgem e desaparecem dando a ver simulacros, quase esboços de uma memória ficção, tal como os filmes lembrados pela personagem Evangelista, exibidos no cinema onde se erguera a sua igreja. Nesse traçado de espaços e tempos se estabelece a jornada de sobrevivência - encontros e perdas - que delineia a saga de uma família.
4. CABALLERO. Cenários liminares, p. 26.

8. MORENO. Agreste, p. 21.
EM TESE BELO HORIZONTE $\quad$ v. $21 \quad$ N. 2 MAIO-A60. 2015 PEREIRA. Uma leitura de escrita traumática em duas dramaturgias [...] $\quad$ P. 136-146 
9. RESENDE. Contemporâneos, p. 27.

10. SÜSSEKIND. Desterritorialização e forma literária, p. 12.
Com efeito, independentemente do sentido operado pelo deslocamento, prevalece o horizonte do incerto, no qual o indivíduo torna-se necessariamente vulnerável. O percurso, tratado às cegas, conduz a zonas de conflito e evidencia de imediato a fragilidade do corpo físico. Assim sendo, torna-se preeminente a relação do corpo que padece e a resolução trágica, anotada frequentemente na multiplicação de atos de violência.

A respeito de uma expressão literária brasileira fortemente marcada pelo imaginário urbano, é sabido que a tópica da violência nos grandes centros urbanos ascende em importância, sendo este um dos pontos de apoio recorrentes pela crítica, a fim de se discutir um olhar obcecado e urgente sobre um presente dominante; "presentificação radical", como sugere Beatriz Resende, " "presentificação restritiva, estática, fundamentada no modelo da coleção", na perspectiva de Flora Süssekind. ${ }^{10}$ Desviando de tais associações, Agreste e BR-3 constroem gradativamente um sentido não cotidiano para a violência, revista dentro de um processo contínuo de abandono, de esvaziamento de referentes, como poderemos observar.

Paralelamente à persistência de atos de violência, e a frequente conclusão pela morte, ditando o senso de tragicidade, destacamos uma igual fragilidade de espírito por parte dos personagens, de elementos que confiram à sua vivência individual a solidez de uma experiência (inter)subjetiva, resultando na sua incapacidade e/ou falha de reflexividade. De maneira que a errância do corpo corresponderia a uma igual errância do $e u$, a uma subjetividade cada vez mais imprecisa.

Com efeito, surge no estudo de Oliveira, focado na relação entre drama e narrativa, a expressão "narrativas do luto". ${ }^{11}$ Tomando por análise textos essencialmente narrados, a saber, Borandá: auto do migrante, de Luís Alberto de Abreu; Assombrações do Recife Velho, de Newton Moreno; e A procissão, de Gero Camilo, o autor verifica em tais obras um silenciamento generalizado de vozes e imaginários, um irrestrito manuseio da perda. O detalhe é lido pelo autor como uma alegoria que ultrapassa a individualidade, ou, como quer Ricœur, encontra o seu equivalente para além da situação patológica de que se ocupa a psicanálise, sustentando a ideia de que identidade pessoal e identidade comunitária constituem-se bipolarmente:

[...] É a constituição bipolar da identidade pessoal e da identidade comunitária que, em última instância, justifica estender a análise freudiana do luto ao traumatismo da identidade coletiva. Pode-se falar em traumatismos coletivos e em feridas da memória coletiva, não apenas num sentido analógico, mas nos termos de uma análise direta. A noção de objeto perdido encontra uma aplicação direta nas "perdas" que afetam igualmente o poder, o território, as populações
11. OLIVEIRA. Trajetórias de migrantes, p. 75.
EM TESE $\quad$ BELO HORIZONTE $\quad$ v. $21 \quad$ N. $2 \quad$ MAIO-AG0. $2015 \quad$ PEREIRA. Uma leitura de escrita traumática em duas dramaturgias [...] $\quad$ P. 136-146

\section{Crítica Literária, outras Artes e Mídias}


12. RICCEUR. A memória, a história, o esquecimento, p. 92. Paul Ricœu se baseia na análise operada por Freud em Luto e melancolia (1915). que constituem a substância de um Estado. As condutas de luto, por se desenvolverem a partir da expressão da aflição até a completa reconciliação com o objeto perdido, são logo ilustradas pelas grandes celebrações funerárias em torno das quais um povo inteiro se reúne. Nesse aspecto, pode-se dizer que os comportamentos de luto constituem um exemplo privilegiado de relações cruzadas entre a expressão privada e a expressão pública. ${ }^{12}$

Nesse sentido, o curso do protagonismo suscita forte remanescência de individualidade, como que se apartando ou particularizando-se das grandes correntes da mobilidade humana. Contrários ao fluxo de ação, condicionada severamente pela imposição da realidade sobre o indivíduo - dado que antecede o horizonte do incerto citado anteriormente a pausa, o detalhe do gesto e o momento emudecido revelam a tendência reflexiva, o voltar-se para si.

Perfuraram o Brasil mais fundo. Desmontaram dos pés no meio da seca. E pensaram que não devia existir um lugar mais árido que aquele. Mas o Nordeste surpreende a gente. Vai ter sempre uma rês mais murcha e um filho mais moribundo. $O$ peito arfava de contentamento e pavor. Era como se inspirassem alegria e expirassem receio. Uma pausa de um silêncio pesado.
Desviavam olhares, cabisbaixos. Não queriam mostrar a dúvida passeando dentro dos seus olhos. Pior: não queriam ver nos olhos do outro a dúvida.

Voltar? Mesmo se quisesse, não saberiam como. As pegadas úmidas já não existiam;

foram sorvidas com força por aquela terra saudosa da água. ${ }^{13}$

13. MORENO. Agreste, p. 21

No referido trecho de Agreste, que pontua o momento de desterro, explicita-se o contraponto entre exterior, cenário e o corpo reagindo a esse, e interior, negativado pelo olhar, pela cabeça baixa. Percebe-se que tal interioridade censurada repercute mediante a tensão situacional, ou acúmulo de tensões que compõem o relato. Essa mesma qualidade de subjetividade será indicativa de um duplo movimento de antecipação: a relação de anos entre ambos, que, descrita através de melindre, termina resvalando na fuga; e a descrição de sentimentos contrários que terminam por sugerir um comportamento desviante, como na dualidade entre contentamento e pavor, alegria e receio, ou ainda nos trechos:

Se chegassem perto, Deus sabe o que

conteceria. Tinha alguma coisa no amor deles

que não devia acontecer. Mas aconteceu. ${ }^{14}$

Se ele tocasse nela? Se ela aceitasse ele?

Às vezes, é preciso muita coragem para dar um passo.

Uma criança brincando onde não devia. ${ }^{15}$

\section{Crítica Literária, outras Artes e Mídias}


16. SARRAZAC. Sobre a fábula e o desvio, p. 86.
De maneira que, como operado, o desejo de reflexão não afirma ou confirma indissociação do coletivo, foco na pulsão individual, mas problematiza sua possibilidade, sugere que corpo físico e corpo subjetivo se estranham, não encontram um denominador comum. Ainda que voltado para dentro, abandonado o cenário, não se concretiza o exercício da reflexão, da consciência da qual se tomaria proveito quando retornada ao externo. Nesse momento, passar-se-ia à mediação em relação ao corpo do outro e ao corpo social, mediação essa que fracassa.

A particularização do protagonismo, rebatido por uma individualidade falha, apontará fortemente, através desse eu errático, para uma alternância da pulsão dramática pelo acontecimento interpessoal, que segue, como dito por Sarrazac, ${ }^{16}$ obliterada "pela relação, pelo combate do homem contra o mundo". Neste caso, não necessariamente relação de combate, mas propriamente relacional, situação de embate, também ele silencioso. Passo a passo, o trajeto expõe a subtração da expressão privada em favor da expressão coletiva, ou histórica, nos termos de Ricœur.

O aporte se dará na violência extremada, quando já em virtude da morte de Etevaldo, sua anatomia feminina se converter em prova de processo, prova da inquisição que se seguirá. Fato que tratamos de uma dramaturgia que se desdobra sobre uma carga lírica dando a ver aparências, no sentido mesmo de aspectos sobre os quais se voltará; ou seja, dramaturgia que avança para voltar sobre si mesma, como que desvelando sua própria ficção.

Ademais, a violência do processo de inquisição tende, por outro lado, a se confundir mesmo com celebração, ao passo que os moradores se convertem num todo unívoco, instituem um evento prolongado ao mesmo tempo que o significam mutuamente. O luto, numa camada outra, desvia-se do nível intersubjetivo da personagem e se reconfigura no movimento coletivo. Anterior ao gesto anônimo de se atear fogo no casebre, o que sustenta a pertinência do todo, afirma-se:

\section{[...] Um grupo velou a madrugada}

inteira com impropérios, xingamentos, escárnios, maldições, pragas. Criaram um ódio.

Desenterraram a pior parte deles.

Desenterraram as piores palavras da língua.

Nem bem a madrugada se punha, trancaram

portas e janelas das casas delas. Envergonhavam-

se delas. Queriam apagá-las de suas memórias.

Cercaram a casa. Enterravam-nas vivas. ${ }^{17}$

A aflição da perda é traduzida em ódio; perda da ordem moral, da ética terrena, da lógica comunitária. A reconciliação com o objeto perdido acontece no gesto concreto

$\begin{array}{lllllll}\text { EM TESE } & \text { BELO HORIZONTE } & \text { v. } 21 & \text { N. } 2 & \text { MAI-AG0. } 2015 & \text { PEREIRA. Uma leitura de escrita traumática em duas dramaturgias [...] } & \text { P. 136-146 }\end{array}$

\section{Crítica Literária, outras Artes e Mídias}


de violência, o atear fogo, contínuo de substituição e expressão do pensamento pela e na ação. $O$ "acting out", concentrando-nos ainda em Ricœur, evoca no autor a relação entre história e violência, na qual o ato violento substitui a lembrança e contraria afirmar que o presente esteja reconciliado com o passado.

Há um detalhe a ser lido no frame das duas mulheres, sendo o deslumbre do indivíduo consigo, na medida em que o processo do luto se dá em sua extensão; há a aflição da perda, assim como a reconciliação, visto que a Viúva se permite observar, pela primeira vez, a nudez de Etevaldo, descobrindo-o ser mulher, tal qual beijar-lhe na boca. Para além de tal lampejo, a referida tragicidade resvala igualmente na completa despessoalização do indivíduo, que se torna unicamente um objeto catártico, ou projeta tal ilusão do coletivo.

O dado reprimido, pressuposto na ação de desenterrar, é justamente a mácula do imaginário, do corpo histórico. A queima do casebre com as duas mulheres dentro, uma morta e outra viva, é a falsa reconciliação, o comportamento repetido. Diferente da "memória lembrança", desenterrar a "pior parte" (dados comportamentais) e as "piores palavras" é memória-repetição, resistente, por sua vez, à crítica.

Jonas, de $B R-3$, não possui melhor final. Sendo empurrado dentro de uma estrutura narrativa híbrida de longa extensão, como a trabalhada por Bernardo Carvalho, a personagem acaba protagonizando uma epopeia invencionária, inventar um personagem para si, um nome, por fim, uma religião. $\mathrm{O}$ desfecho está no ato suicida, tendo angariado para si o título de traidor e assassino de seus entes. "Tudo em que eu toco morre”, como sentença disfórica crônica. O corpo enforcado numa jangada segue pelo rio num sábado de aleluia, e confundido com um boneco de Judas, é crivado de tiros por todo tipo de gente. A sequência aparece na primeira versão do texto de Bernardo Carvalho como prólogo, como verificado no excerto reproduzido na revista Subtexto.

BR 3 (primeira versão)

Prólogo. Malhação de Judas.

Do lado das margens do rio começa a surgir gente de todos os tipos e de todas as classes. Homens, mulheres, velhos e crianças, todos com bandeirinhas coloridas nas mãos. Mulheres com colares de pérolas saem de carros conduzidos por motoristas uniformizados e descem correndo para a margem puxando os filhos pelas mãos (vêm acompanhadas de seguranças armados). Motoboys largam suas motos no alto e descem até o rio, com bandeirinhas nas mãos. Favelados com seus filhos correm para o rio, com bandeirinhas nas mãos. Todos se aglomeram nas margens para ver alguma coisa. Esperam, ansiosos, a chegada de alguma coisa, ou alguém, que vem pelo
EM TESE
BELO HORIZONTE
v. 21
MAIO-AGO. 2015
PEREIRA. Uma leitura de escrita traumática em duas dramaturgias [...]
P. $136-146$

N. 2

Crítica Literária, outras Artes e Mídias 
rio. Uma criança aponta para um dos lados, rio acima, e grita: Lá vem ele! Todos ficam em silêncio. Lá de longe vem vindo uma jangada com um boneco pendurado num mastro. Os adultos tiram suas armas da cintura, dos bolsos, de dentro das camisas, etc. As mães tiram as pistolas de dentro das bolsas. Entregam as pistolas para as crianças. Todos estão armados, ricos e pobres, adultos e crianças. Quando a jangada passa pela multidão, começam a atirar no boneco. Uma saraivada de balas. Gritam: Judas! Judas! Conforme a jangada avança eles também correm pelas margens, tentando acompanhá-la, rindo e atirando. E no meio da salva de tiros, as próprias pessoas começam a cair, sem saber de onde vêm, as balas. Os da margem esquerda matam os da margem direita e vice-versa sempre rindo, sem se dar conta, até não sobrar mais ninguém de pé. ${ }^{18}$

Em sua versão final, a sequência se concentra de maneira sucinta na última cena, "Brasília. Às margens do lago. Ao fundo, o Congresso Nacional". Nela, um senador em entrevista coletiva tenta discorrer sobre o tráfico animal. Há um coro, inclusas as personagens mortas, que repete "puna e coíba", termos retirados da fala do próprio senador, impedindo-o de prosseguir. Já na companhia de sua esposa, relata ter comprado terras no Acre, em plena decadência pela derrocada da extração de borracha, afirmando que "o homem precisa tanto de madeira quanto de sangue para viver. A gente nasceu para queimar". ${ }^{19}$ A história de Jonas é referida pela esposa, tendo-a ouvido no rádio. Defende que todos acreditaram se tratar de um boneco, por isso atiraram nele, "como há cem anos".

A morte de Jonas como se dá aproxima-o em demasiado da referência bíblica: o destino irremediável da morte, como no Jonas bíblico, e a corporificação do boneco de Judas em homem. A composição, em última instância, desvia-o para fora da história e reforça uma situação mítica, como se se tratasse de uma condução coerente para a impossibilidade de solução. A jangada na qual Jonas segue enforcado cruza finalmente com o pedalinho que leva o Senador e sua esposa, que não a veem. A frase é definitiva: "é como se a jangada e o pedalinho estivessem em dimensões diferentes".

O corpo coletivo definindo evento aparece nas duas situações que se cruzam: o costume expresso pela data católica e o público/coro reunido para o pronunciamento. Novamente verifica-se o exercício da memória repetida, denotada explicitamente na indicação temporal. A tragicidade está em não se perceber no fluxo histórico, repetindo frases sem daí tirar nenhum sentido e crivando de balas um homem acreditando ser um boneco. Em sua versão inicial é ainda mais contundente, na medida em que todos os presentes na "celebração" se tornam simultaneamente algozes e vítimas. 
20. GUMBRECHT. Produção de presença, p. 114-115.
A impossibilidade da consciência subjetiva e a continuidade de um inconsciente coletivo projetam uma atenção especial ao corpóreo. Para Gumbrecht, diferentes formas de "apropriação-do-mundo" correspondem, por sua vez, a diferentes ideais de cultura, um de sentido e outro de presença. Obviamente, tal relação pressupõe um agente de apropriação e seu respectivo objeto. Tendo como referência uma cultura idealizada pela presença, o gesto de apropriação passa mesmo pelo ato em si, a exemplo:

Penetrar coisas e corpos - ou seja, contato corporal e sexualidade, agressão, destruição e assassínio - constitui um segundo tipo de apropriação-do-mundo, no qual a fusão de corpos ou com coisas inanimadas é sempre transitória e, por isso, abre necessariamente um espaço de distância ao desejo e à reflexão. ${ }^{20}$

O "receio", o "medo", a distância à "reflexão" definem a possibilidade do inverso, ou seja, que o agente de apropriação se torne o objeto desse mesmo tipo de apropriação. Fato que corrobora com desconfortos comunicativos, assuntos silenciados ou tabus. O que se percebe, a exemplo de Agreste e $B R-3$, é ausência de tal pressuposto reverso, para o qual não há tempo. Os movimentos são osmóticos, a mão que propaga o fogo é indiferente, assim como a procedência dos tiros.
Perda e reconciliação não se diferem; perde-se pela violência e se reconcilia pela violência.

É através da morte, portanto, que se afirma o conjunto, que se identifica novamente o traço solidário, a exemplo de Agreste, perdido, destituído pela quebra da ética sertaneja e pela negação - impossibilidade de reconhecimento - do eu e do outro. A gravidade, portanto, com que se delineia a constante do fator morte, numa tomada que requer para si certa legitimidade do trágico, não figura, de fato, ou não pressupõe o movimento de luto em sua plenitude, como afirma Oliveira, para que as dramaturgias sejam assim definidas do luto -, o que, por outro lado, também nos parece supor uma simplificação temática.

A não reconciliação com a perda, o afunilamento do tempo presente, desalinhando-o com o passado e futuro, deixa ver como dado essencial o traumatismo, conquanto o luto é movimento interrompido. $\mathrm{O}$ trauma exposto pelo retorno do incompreendido, entretanto, não servirá à busca da solução como se pode verificar na clínica psicanalítica. Reviver, repetir como essência da harmonia, do empenho em se pontuar novamente, ou ineditamente, com clareza, o eu e o outro, é anulado pela incapacidade e falha de reflexão reforçada pelas dramaturgias. Trauma, portanto, que localizado fora do ego, afasta-se da fala, da cognição, passando ao já citado 
21. GUATTARI; ROLNIK Micropolítica, p. 323. acting out, como são os comportamentos/ritos recalcados que finalizam tanto Agreste como BR-3.

A perda da identidade em golpes contínuos, falseando a promoção da reconciliação... a movência se torna imposta, alternada em assentamentos provisórios nos quais o indivíduo se liga ao ambiente no limite do necessário, não o pertence. Portanto, não há luto, apenas traumatismo.

Se a ideia de território pressupõe um vetor de saída do mesmo, e se tal saída pressupõe ao menos o esforço de se territorializar em outra parte - princípio para o conceito deleuze-guattariano de desterritorialização -, enquanto apropriação, "espaço vivido" e "sistema percebido", ${ }^{11}$ o gesto não encontraria em definitivo o seu objetivo, operação nunca bem-sucedida. Impossibilidade de se reterritorializar como máxima que circunda as questões de identidade - individual e coletiva - e, logo, de pertencimento.

Como último apontamento, e ampliando-se à perspectiva dramatúrgica, naquilo que transparece de condição criativa, o traumático estaria para além do nível ficcional. A sugestão recai especificamente sobre uma possível visão particularizada de presente, que assim como no trauma revela haver uma ruptura da lógica corrente e progressiva do tempo histórico. Ainda que tratemos de uma produção literária surgida no âmbito de um imaginário criativo urbano, no qual a violência e a morte pudessem assumir um caráter de presentificação mais cotidiana, banal, prevaleceria um contorno de presente assombrado pelo passado e de futuro incerto. Em alguma medida, formas de escrita, também elas, sugerindo impossibilidade de pertencimento, de territorialização.

\section{REFERÊNCIAS}

CABALLERO, lleana Diéguez. Cenários liminares: teatralidades, performances e política. Trad. Luis Alberto Alonso e Angela Reis. Uberlândia: EDUFU, 2011.

CARVALHO, Bernardo. BR-3. Original do autor.

GUATTARI, Félix; ROLNIK, Suely. Micropolítica: cartografias do desejo. Petrópolis: Vozes, 1993.

GUMBRECHT, Hans Ulrich. Produção de presença: o que o sentido não consegue transmitir. Trad. Ana Isabel Soares. Rio de Janeiro: Contraponto; Ed. PUC-Rio, 2010.

MORENO, Newton. Agreste, Body Art, A refeição. São Paulo: Aliança Francesa - Consulado Geral da França em São Paulo: Imprensa Oficial do Estado de São Paulo, 2008.

OLIVEIRA, Kildervan Abreu de. Trajetórias de migrantes narrativa e questoes de gênero na dramaturgia brasileira contemporânea. 2006. 89 p. Dissertação (Mestrado em Artes) Escola de Comunicação e Artes, Universidade de São Paulo, São Paulo, 2006. 
RESENDE, Beatriz. Contemporâneos: expressões da literatura

brasileira no século XXI. Rio de Janeiro: Casa da Palavra;

Biblioteca Nacional, 2008.

RICCEUR, Paul. A memória, a história e o esquecimento. Trad Alain François. Campinas: Unicamp, 2008.

SARRAZAC, Jean-Pierre. Sobre a fábula e o desvio. Trad. e org. Fátima Saadi. Rio de Janeiro: 7 Letras; Teatro do Pequeno Gesto, 2013.

A invenção da teatralidade. Sala Preta, São Paulo, v. 13 p. 56-70, 2013

O futuro do drama. Trad. Alexandra Moreira da Silva. Lisboa: Campo das letras, 2006. 240 p. (Cadernos Dramat, 9).

SÜSSEKIND, Flora. Desterritorialização e forma literária. Sala

Preta, São Paulo, v. 4, p. 11-29, 2004

TOSCANO, Antônio Rogério. Agreste: uma dramaturgia desejante. Sala Preta, São Paulo, v. 4, p. 105-113, 2004. 